Experimental Psychology, 1965, 69 624-629

CERVIN, V. B.. SMITH, A. A., \& KABISH, C. H. Multiple S-R apparatus for individual and social learning. Psychological Reports, 1965, 17 , 499-510.

HAYGOOD, R. C., \& BOURNE, L. E., JR Attribute- and rule-learning aspects of conceptual behavior. Psychological Review, 1965,72, 175-195.

HUNT, E. B., MARIN, J., STONE, P. J. Experiments in induction. New York: Academic Press, 1966.

NEISSER, U., \& WEENE, P. Hierarchies in concept attainment. Journal of
Experimental Psychology, 1962, 64. $640-645$

ROWETON, W. E., \& DAVIS, G. A. Effects of preresponse interval, postinformative feedback interval, and problem difficulty on the identification of concepts. Journal of Experimental Psychology, 1968, 78 , $642-645$.

WINER, B. J. Statistical principles in experimental design. New York: McGraw-Hill, 1962.

$$
\text { NOTE }
$$

1. If a $S$ had not reached the criterion of 16 consecutive correct responses, he was assigned a score of 96 for the purpose of this analy sis.

\title{
Age and the distribution of observing responses*
}

\author{
A. J. SANFORD and A. JOHN MAULE \\ The University, Dundee DD1 4HN, Angus, Scotland
}

It is hypothesized on the basis of previous work that older people may be under greater stimulus control in a multisource monitoring situation with a signal frequency imabalance across sources than are younger Ss. The results obtained refute this hypothesis and show that older people are less selective. Explanations in terms of probability learning and arousal level are discussed.

The manner in which observing responses $(O R)$ are distributed across sources by $\mathrm{Ss}$ is known to be a function of the signal probability distribution across sources. If a man has to monitor the states of several different machines as part of a control process, then he is often more likely to look at a machine which goes wrong often than at one which goes wrong infrequently. The extent to which this type of stimulus control of the OR occurs as a function of stimulus (fault) rate and rate of observation has been investigated by Hamilton (1969). Hamilton used a simulation of an industrial fault-finding situation with three "machines" whose states had to

*This research was financed by $\mathrm{SSRC}$ Grant No. HR/665/1 under the general direction of Professor S. Griew.

tThe authors are grateful to the Royal Dundee Liff Hospital and Dundee Old Peoples' Welfare Committee for assistance with enlisting $\mathrm{Ss}$. be monitored by testing each one through a buttonpress operation (this is the operational OR). He found that Ss' OR distribution across the sources was not influenced by signal probability at each source $(.6, .3, .1)$, when the average time between signals was long and Ss could observe at their own rates. However, when signal rate was increased, or Ss were restricted in the rate at which they could observe, they became more selective and tended towards matching signal probability with their OR distribution. The salient variable in controlling selectivity, argued Hamilton, was the average number of samples made before a signal was detected.

This carries important implications for aging studies. One of the best known facts of psychological research in aging is that older people are slower at nearly all tasks they are given (e.g., Birren \& Riegel, 1962). In an OR situation there is every reason to suppose that the same rule will apply. The question examined here is first whether older people are slower than young in an OR situation, and secondly, whether they are more selective as a result. Since the optimum distribution of $O R$ is related to signal probability regardless of speed of observing and signal rate (Hamilton, 1967, p. 45), a greater tendency to structure in old Ss would imply a more economical distribution of effort as a function of age. The possibility of older people's using knowledge of probabilities to overcome the failing sensory-motor skill system was suggested some time ago by Griew $(1962,1968)$.

\section{METHOD}

Twelve old (mean age 69.7 years) and 12 young (mean age 22.8 years) people were voluntary unpaid Ss. ${ }^{1}$ Ss sat in a darkened room facing a vertically mounted $4 \times 4 \mathrm{ft}$ blackboard upon which were arranged three pinhead-size lights (sources) in an equilateral triangle of 30 -in. sides. Viewing distance was $4 \mathrm{ft}$. At knee level, immediately before the $S$, was a control panel with three "sample buttons" mounted on it in an equilateral triangle (8-in. sides), each corresponding to one of the lights. When pressed, the appropriate light would flash (red) briefly if a fault was present on that channel. No flash occurred if no fault was present. Mounted immediately below each sample button was a corrector button. If a fault was located, the appropriate corrector button had to be pressed, otherwise the fault would remain and would be seen again the next time the channel was sampled. Each time a sample button was pressed, the OR was recorded on one of three counters. In this way, the number of ORs to each channel was recorded.

Faults occurred at a mean rate of one/12 sec, randomized between 6.4 and $17.6 \mathrm{sec}$. Probabilities of faults occurring were: Source $1=.6$; Source $2=.3 ;$ Source $3=.1$. In a period of $36 \mathrm{~min}$, approximately 180 faults were presented.

Ss attended two sessions each of about $40 \mathrm{~min}$ duration. Session 1 was designed especially to help $S s$ to understand the analogy of losing money when faults occurred but were not corrected. Ss had a digital counter before them which started clocking up at a rate of one increment per second when a fault occurred. This counter bore the caption " $f$ lost." Ss saw that they were losing (hypothetical) money, and pressed the sample buttons to find where the loss occurred. On finding the faulty machine they simply pressed the corrector button. A brief session at this ensured that all Ss understood 
Table 1

Summary of Findings. $P(O)_{1}$ and $P(O)_{2}$, refer to the probabilities of observing the most frequent and intermediate source. OR rate refers to number of observing buttonpresses per 2-min epoch.

\begin{tabular}{|c|c|c|c|c|c|}
\hline Group & $\begin{array}{c}\text { Test } \\
\text { Third }\end{array}$ & $P(O)_{1}$ & $\mathrm{P}(\mathrm{O})_{2}$ & $\mathrm{P}(\mathrm{O})_{3}$ & $\begin{array}{c}\text { OR Rate } \\
\text { (OR/2 Min) }\end{array}$ \\
\hline $\begin{array}{l}\text { Old Ss } \\
(N=12)\end{array}$ & $\begin{array}{l}1 \\
2 \\
3\end{array}$ & $\begin{array}{l}.36 \\
.37 \\
.38\end{array}$ & $\begin{array}{l}.34 \\
.36 \\
.36\end{array}$ & $\begin{array}{l}.30 \\
.27 \\
.26\end{array}$ & $\begin{array}{l}65 \\
83 \\
91\end{array}$ \\
\hline $\begin{array}{l}\text { Young Ss } \\
(\mathrm{N}=12)\end{array}$ & $\begin{array}{l}\mathbf{1} \\
\mathbf{2} \\
\mathbf{3}\end{array}$ & $\begin{array}{l}.39 \\
.43 \\
.45\end{array}$ & $\begin{array}{l}.34 \\
.35 \\
.34\end{array}$ & $\begin{array}{l}.27 \\
.22 \\
.21\end{array}$ & $\begin{array}{l}104 \\
130 \\
138\end{array}$ \\
\hline
\end{tabular}

Note-For convenience of analysis, the data are divided into three test periods of 12 min each. $P(O)_{1}$, the probability of observing the high probability source, is used as an index of selectivity in age comparisons.

what was meant by and implied by a fault. In the main session, the counter was put where it could not be seen by Ss, and they were told to sample as quickly as they wished, and to find faults as soon as possible and rectify them. They were further told that machines would develop faults at different rates and that they were to remember this in trying to find which machines were faulty. Ss were told that they would be shown how they scored at the end of the test. Machine-probability combinations were randomized according to a Latin square design across Ss.

\section{RESULTS}

All results considered here are given in Table 1.

\section{OR Rate}

As anticipated, the rate of observing

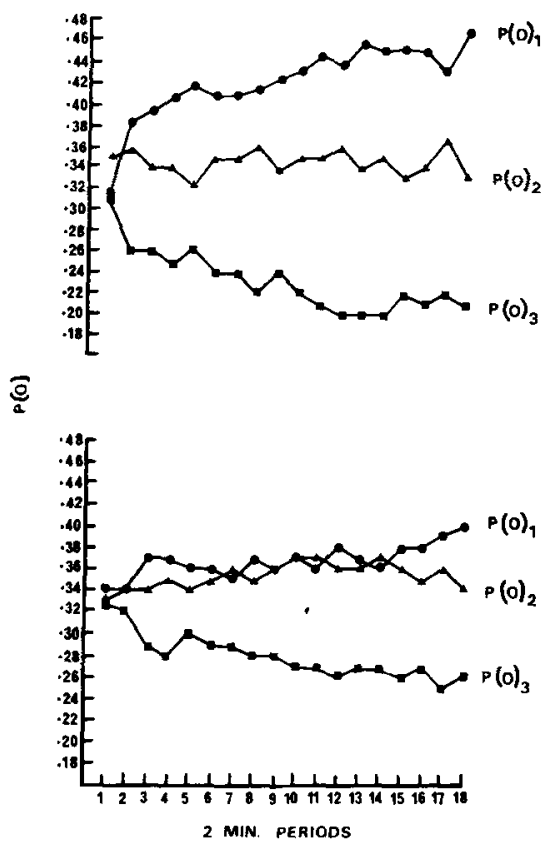

Fig. 1. $P(O)_{1}, P(O)_{2}$, and $P(O)_{3}$, the probabilities of observing the most, middle, and least frequent sources as a function of time on test. Upper graph, young Ss; lower graph, old Ss. was much slower in the case of the older Ss. The difference is significant in each third of the test $(p<.002$; Mann-Whitney $U$ tests), and there is no interaction between age groups and time on test, showing that the average difference in observing rate was not narrowed by practice. Selectivity

It is absolutely clear that older Ss do not show such selective behavior as young Ss (see Fig. 1). Some selectivity is present in the distribution of both groups, however. Application of the Friedman analysis of variance (Siegel, 1956) shows that source fault probability did have an effect on the distribution of ORs in the case of old $(\mathrm{p}<.05)$ and young $(\mathrm{p}<.001)$ Ss. Separate analyses of this kind on each test third shows exactly the same pattern of results. In the second and third thirds of test, the difference between age groups in the percentage of responses to the high probability source is significant $(p<.01$, two-tailed, both cases) confirming that the older groups are less selective than the younger group in this experiment. In the first third, the difference is not significant.

\section{CONCLUSIONS}

In this experiment there is clear evidence that the predicted greater selectivity in older Ss is not the case. It is unlikely that the results can be accounted for in terms of poorer probability evaluation and learning on the part of the older groups, since Sanford \& $O^{\prime}$ Donnell $^{1}$ have shown that there is no difference between old and young Ss' guesses in both two- and three-choice prediction (matching) tasks.

At this stage it is difficult to decide which variable might account for the lessening in selectivity with age. Several possibilities suggest themselves. First, as can be seen from the young Ss' data, Ss do not match signal frequencies. Hamilton (1967) has shown that the optimal distribution of OR is $5: 3: 2$ to the $6: 3: 1$ signal distribution, but the gain of being selective in terms of speed of detection is not very great compared with the detrimental effects of being overselective. It is therefore imperative to investigate the situation further with greater differences in signal frequency differential between the sources.

In postulating a possible greater selectivity in old $\mathrm{Ss}$, it was assumed that old Ss would be effectively the same as young Ss who were externally restricted in their rates of observing However, it may well be the case that the older Ss, although slower, were processing and still acting as quickly as some central process would allow rather than choosing to sample more slowly. This would imply that so far as the Ss were concerned, they were all operating as quickly as possible, unlike the situation where there is an external pacing restriction when Ss are forced to wait. This may account for the failure to find greater selectivity in old Ss.

It remains to be seen why old Ss are actually less selective, given that they evaluate probabilities in the same way as young Ss. One theoretically intriguing possibility is that the differences in selectivity may be due to a lower arousal level in the old group. It has been shown by Hockey (1969) that underaroused Ss (sleep deprived) are less selective than controls, while aroused Ss (noise stimulated) are more selective in the OR situation. Whether this interpretation is a useful one will be shown by parametric studies now under way, using two age groups in a variety of monitoring tasks.

\section{REFERENCES}

BIRREN, J. F., \& RIEGEL, K. F. Age differences in response speed as a function of controlled variations of stimulus condition: Lights, numbers. letter, colors, syllables, words and word relationships. In $C$. Tibbitts and $W$. Donahue (Eds.), Social and psychological aspects of aging. New York: Columbia University Press, 1962. Pp. 751-758.

GRIEW, $S$. The learning of statistical structure: A preliminary study in relation to age. New York: Columbia University Press, 1962. Pp. 764-769.

GRIEW, S. Age and the matching of signal frequency in a two-channel detection task. Joumal of Gerontology, 1968, 23, 93-96.

HAMILTON, P. Selective attention in a multisource monitoring task. Unpublished PhD thesis, University of St. Andrews, Scotland, 1967.

HAMILTON, $P$. Selective attention in multisource monitoring tasks. Journal of Experimental Psychology, 1969, 82. 34-37.

HOCKEY, G. R. J. Environmental stress and attention to complex visual displays. Unpublished PhD thesis, University of Cambridge, England, 1969.

SIEGEL, S. Non-parametric statistics. New York: McGraw-Hill, 1956. NOTE

1. Sanford, A. J., and O'Donnell, L. Age effects in simple prediction behaviours. In preparation. 